\title{
A systems biology analysis of brain microvascular endothelial cell lipotoxicity
}

\author{
Hnin H Aung ${ }^{1+}$, Athanasios Tsoukalas ${ }^{2,3+}{ }^{+}$, John C Rutledge ${ }^{1}$ and llias Tagkopoulos ${ }^{2,3^{*}}$
}

\begin{abstract}
Background: Neurovascular inflammation is associated with a number of neurological diseases including vascular dementia and Alzheimer's disease, which are increasingly important causes of morbidity and mortality around the world. Lipotoxicity is a metabolic disorder that results from accumulation of lipids, particularly fatty acids, in non-adipose tissue leading to cellular dysfunction, lipid droplet formation, and cell death.

Results: Our studies indicate for the first time that the neurovascular circulation also can manifest lipotoxicity, which could have major effects on cognitive function. The penetration of integrative systems biology approaches is limited in this area of research, which reduces our capacity to gain an objective insight into the signal transduction and regulation dynamics at a systems level. To address this question, we treated human microvascular endothelial cells with triglyceride-rich lipoprotein (TGRL) lipolysis products and then we used genome-wide transcriptional profiling to obtain transcript abundances over four conditions. We then identified regulatory genes and their targets that have been differentially expressed through analysis of the datasets with various statistical methods. We created a functional gene network by exploiting co-expression observations through a guilt-by-association assumption. Concomitantly, we used various network inference algorithms to identify putative regulatory interactions and we integrated all predictions to construct a consensus gene regulatory network that is TGRL lipolysis product specific.

Conclusion: System biology analysis has led to the validation of putative lipid-related targets and the discovery of several genes that may be implicated in lipotoxic-related brain microvascular endothelial cell responses. Here, we report that activating transcription factors 3 (ATF3) is a principal regulator of TGRL lipolysis products-induced gene expression in human brain microvascular endothelial cell.
\end{abstract}

Keywords: Activating transcription factor 3, Microarray, Triglyceride-rich lipoprotein, Blood-brain barrier

\section{Background}

The estimated prevalence of dementia of persons greater than 70 years of age is $14.7 \%$ [1]. The yearly cost attributable to dementia is between $\$ 43,000 /$ patient and $\$ 70,000 /$ patient and the total monetary cost of dementia in 2010 was between $\$ 157$ billion and $\$ 215$ billion. Add to this, the enormous personal and emotional cost to, not only the patient, but also to family, friends, and co-workers, and we have a national tragedy that is about to unfold as the baby boomers transition to the elderly. These financial

\footnotetext{
* Correspondence: iliast@ucdavis.edu

${ }^{\dagger}$ Equal contributors

${ }^{2}$ UC Davis Genome Center, University of California, Davis, CA 95616, USA

${ }^{3}$ Department of Computer Science, University of California, Davis, CA 95616, USA

Full list of author information is available at the end of the article
}

and personal costs place dementia on par with the costs attributable to ASCVD and cancers.

One of the potential inducers of neurovascular inflammation is triglyceride-rich lipoprotein (TGRL) particles and their lipolysis products [2]. Lipoprotein lipase (LpL) is anchored to the brain microvascular endothelium, where it binds and hydrolyzes TGRL particles to smaller lipolysis products, such as fatty acids [3]. TGRL lipolysis products are generated at the luminal surface of the vascular endothelium and the lipolysis products in high physiological and pathophysiological concentrations can potentially injure the endothelium directly, increase the permeability of the blood-brain barrier (BBB), and/or injure astrocytes and neurons within the brain. Our studies have shown that TGRL lipolysis products have a dramatic effect on endothelial cell injury, which is of much greater magnitude than TGRL particles, such as chylomicrons and VLDL [4]. 
To explore neurovascular lipotoxicity further, we treated human brain microvascular endothelial cell (HBMVEC) with TGRL lipolysis products and then we used genome-wide transcriptional profiling to obtain transcript abundances over four conditions. We then identified regulatory genes and their targets that have been differentially expressed (DE) through analysis of the datasets with various statistical methods (Figure 1). We created a functional gene network by exploiting co-expression observations through a guilt-by-association assumption. Concomitantly, we used various network inference algorithms to identify putative regulatory interactions and we integrated all predictions to construct a consensus gene regulatory network that is TGRL lipolysis product specific. This analysis has led to the validation of putative lipid-related targets and the discovery of several genes that may be implicated in TGRL lipolysis-related lipid response. Our system biology analysis also identified that activating transcription factors 3 (ATF3) is a principal regulator and induces expression of downstream inflammatory response genes in HBMVEC treated with TGRL lipolysis products.

\section{Results}

As shown in Figure 2, there is some overlap between the different DE techniques used, as well as differences in the top gene candidates identified, due to the different features and underlying statistical assumptions of each

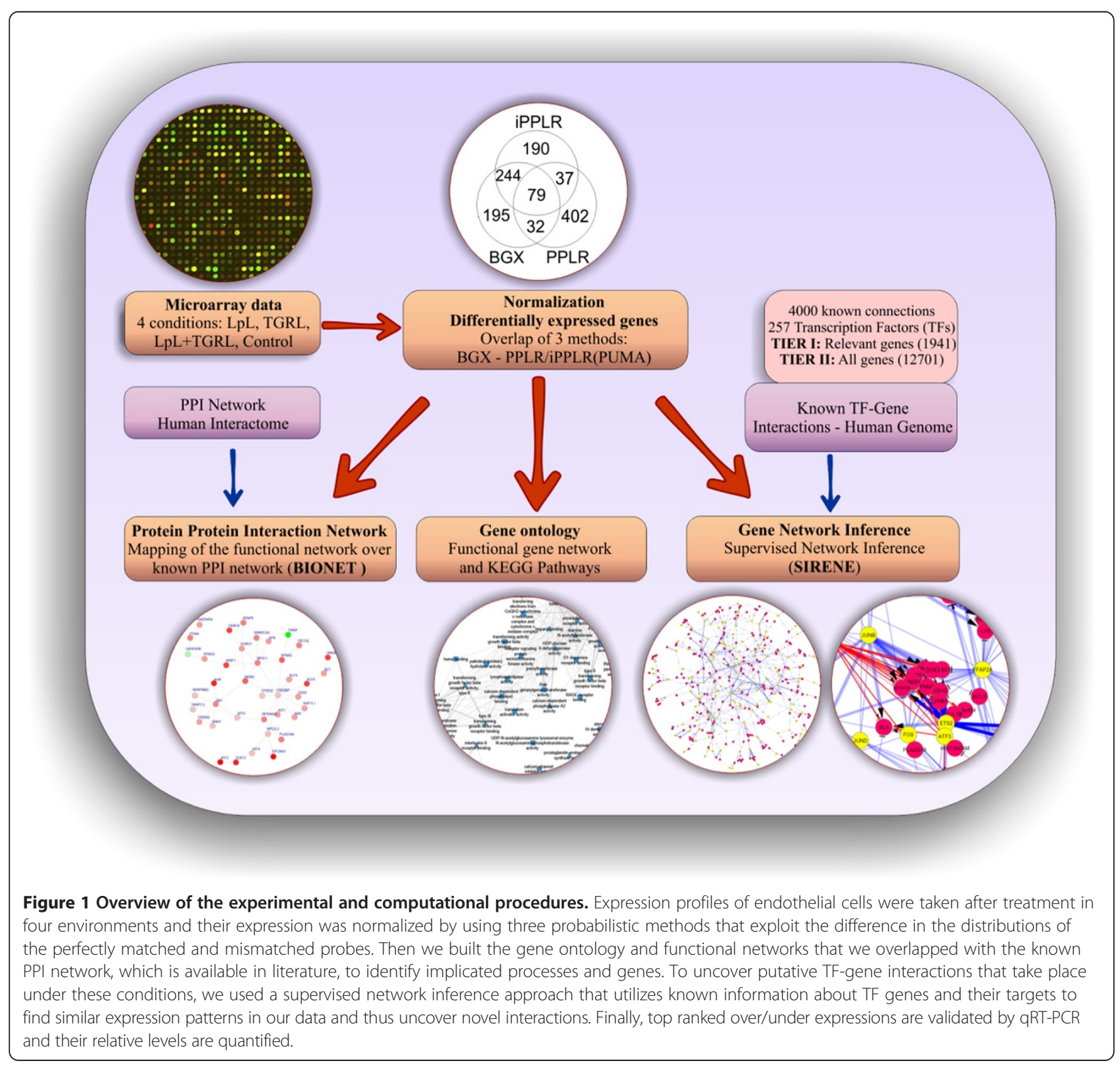



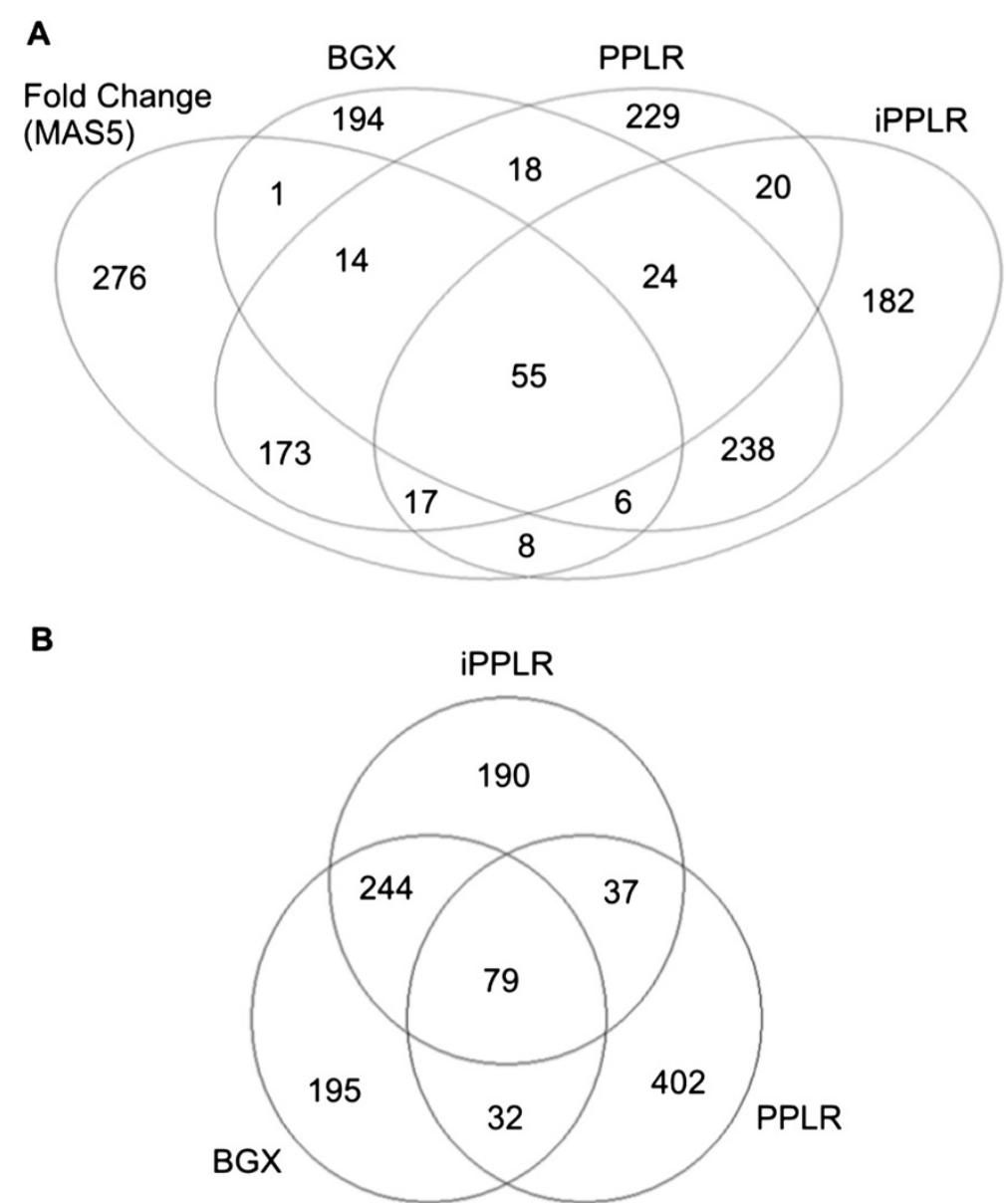

Figure 2 Venn diagrams on differentially expressed (DE) genes. (A) The most highly-ranked 550 genes from all available methods; (B) Venn diagram shows overlap for probabilistic-only methods that were used to identify the consensus list of DE genes. The gene cut-off (550 genes) corresponds approximately to a p-value of 0.05 or lower in all methods.

technique. Table 1 depicts the top 20 genes that have the highest DE between the treatment with the combination of TGRL and LPL (TGRL lipolysis products), and the control (media-only) that are within the statistical cut-off value $\left(\mathrm{p}\right.$-value $<10^{-4}$ ), over all techniques. Consistent with our previous results in endothelial cells [5], ATF3 shows clear up-regulation after TGRL lipolysis product treatment.

The 79 DE genes that have been in parallel identified from all methods form a functional gene network with 54 functional categories that are significantly over-represented in this gene set, which also implicates 12 KEGG pathways (Figure 3A). We integrated the expressionderived relationships with the known protein-protein interaction (PPI) network that was extracted by using the BIONET Bioconductor package [6] and the Interactome Library [7] (Figure 3C). In addition, we used a support vector machines (SVM) method called SIRENE [8] together with a dataset where we amassed of all known TF-gene interactions ( 4000) in order to construct a condition-specific
Gene Regulatory Network (GRN) associated with TGRL lipolysis treatment (Figure 4). The resulting network has 151 TFs, 272 target genes ( $\mathrm{X}$ and $\mathrm{Y}$ up- and down-regulated, respectively), 236 inhibitory interactions $(\rho<-0.25)$, and 265 activatory interactions $(\rho>0.25)$.

\section{Genome-wide analysis of TGRL lipolysis-treated HBMVEC}

Differential analysis of gene expression data showed that HBMVEC treated with either LpL or TGRL altered the expression of a small percentage of genes $(3.01 \%$ and $4.03 \%$, respectively, when compared to control). TGRL + LpL (TGRL lipolysis products) treatment affected the expression of $5.61 \%$ of all genes detected $(\sim 14,500)$. Functional classification of genes modulated by lipolysis product $(\mathrm{TGRL}+\mathrm{LpL})$ treatment identified multiple functional classes including transcription factors, inflammatory responses, apoptosis, cell cycle, cell proliferation, ion metabolism, lipid metabolism, kinase activity, signalling pathways, DNA binding, protein binding, protein folding, and proteins of unknown function. 
Table 1 Top 20 differentially expressed (DE) genes (consensus over three methods); Numbers denote the fold-change (FC) between the TGRL + LpL condition and the control (media-only)

\begin{tabular}{|c|c|c|c|c|c|}
\hline GENE SYMBOL & GENE NAME & iPPLR FC & BGX FC & PPLR FC & p-values \\
\hline ATF3 & Activating transcription factor 3 & 1,86 & 2,67 & 3,06 & $10^{-14}$ \\
\hline BHLHE40 & Basic helix-loop-helix family, member e40 & 0,35 & 0,23 & 0,32 & $10^{-9}$ \\
\hline PRNP & Prion protein & 1,47 & 3,09 & 3,89 & $10^{-8}$ \\
\hline CSGALNACT2 & Chondroitin sulfate $\mathrm{N}$-acetylgalactosaminyltransferase 2 & 1,48 & 3,90 & 4,36 & $10^{-8}$ \\
\hline ADD3 & Adducin 3 (gamma) & 1,61 & 4,29 & 4,52 & $10^{-7}$ \\
\hline MAD2L 1 & MAD2 mitotic arrest deficient-like 1 (yeast) & 1,07 & 3,49 & 3,31 & $10^{-7}$ \\
\hline ADAM9 & ADAM metallopeptidase domain 9 & 1,22 & 3,19 & 3,38 & $10^{-7}$ \\
\hline ZNF217 & Zinc finger protein 217 & 1,83 & 6,04 & 4,94 & $10^{-7}$ \\
\hline DDIT3 & DNA-damage-inducible transcript 3 & 1,11 & 2,50 & 2,83 & $10^{-6}$ \\
\hline STK39 & Serine threonine kinase 39 & 1,13 & 2,94 & 3,81 & $10^{-6}$ \\
\hline LIMS1 & LIM and senescent cell antigen-like domains 1 & 1,14 & 3,03 & 3,10 & $10^{-6}$ \\
\hline MMRN1 & Multimerin 1 & 1,62 & 2,95 & 3,34 & $10^{-5}$ \\
\hline CSGALNACT2 & Chondroitin sulfate $\mathrm{N}$-acetylgalactosaminyltransferase 2 & 1,06 & 3,99 & 3,63 & $10^{-5}$ \\
\hline PAIP1 & Poly(A) binding protein interacting protein 1 & 1,04 & 2,34 & 2,80 & $10^{-5}$ \\
\hline HDGFRP3 & Hepatoma-derived growth factor, related protein 3 & 1,05 & 2,26 & 2,84 & $10^{-5}$ \\
\hline HES1 & Hairy and enhancer of split 1, (Drosophila) & 0,56 & 0,34 & 0,42 & $10^{-5}$ \\
\hline FRMD4B & FERM domain containing 4B & 1,13 & 2,80 & 2,92 & $10^{-5}$ \\
\hline DUSP6 & Dual specificity phosphatase 6 & 1,08 & 3,03 & 2,71 & $10^{-4}$ \\
\hline PRKAR1A & Protein kinase, cAMP-dependent, regulatory, type I, alpha & 1,12 & 2,69 & 2,73 & $10^{-4}$ \\
\hline ТTC37 & Tetratricopeptide repeat domain 37 & 1,13 & 2,72 & 2,48 & $10^{-4}$ \\
\hline
\end{tabular}

\section{Differentially expressed transcription factors}

TGRL lipolysis products activated genes encoding transcription factors including activating transcription factor (ATF3), ATF4, ATF2, DNA damage-inducible transcript 3 (DDIT3), CREB binding protein (CREBBP), Krueppel-like factor 4 (KLF4), KLF5, aryl hydrocarbon receptor (AHR), peroxisome proliferator-activated receptor delta (PPARD). ATF3 is a member of the mammalian activation transcription factor/cAMP responsive elementbinding (CREB) protein and a member of the ATF family of transcription factors. This gene is induced by a variety of signals including many of those encountered by cancer cells, and is involved in the complex process of cellular stress response [9] and post-translational modifications have been established. For instance, it has been reported previously that upon UV irradiation, two transcription factors, c-Jun and ATF2, are phosphorylated by the JNK/SAPK family of stress-induced kinases [10]. Many stress responses have been studied in tissue culture cells by using signals including UV irradiation [11], cytokines [12], and modulated by gadd153/Chop10 [13]. ATF4 encodes a transcription factor that was originally identified as a widely expressed mammalian DNA binding protein. Recently it has been found that ATF4 mediates hyperglycemia-induced endothelial inflammation and retinal vascular leakage in mouse [14].
Up-regulation of ATF3 (19.6-fold) and ATF4 (3.6-fold) by TGRL lipolysis in HBMVEC was confirmed by qRT-PCR (Figure 5A).

CREB binding protein (CREBBP) is ubiquitously expressed and is involved in the transcriptional coactivation of many different transcription factors and known to play critical roles in embryonic development, growth control, and homeostasis by coupling chromatin remodeling to transcription factor recognition. Transforming growth factor- $\beta$ signalling pathways mediate epithelial-mesenchymal transition are dependent on the transcriptional co-activator CREBBP [15]. CREBBP was increased (1.1-fold) but not significantly up-regulated by TGRL lipolysis products (data not shown). DNA damage-inducible transcript 3 (DDIT3; 5.6-fold upregulation; Figure $5 \mathrm{~A}$ ) is a member of the CCAAT/enhancer binding proteins (C/EBPs) (CHOP) family of transcriptional factors that regulate cell cycle and apoptosis.

Krueppel-like factor 4 (KLF4; 4-fold up-regulation; Figure $5 \mathrm{~A}$ ) is known to be endothelial Kruppel-like zinc finger protein. KLF4 differentially regulates pertinent endothelial targets and important regulators of vascular homeostasis and atherothrombosis [16]. Kruppel-like factor 4 regulates endothelial activation in response to pro-inflammatory stimuli [17]. Peroxisome proliferatoractivated receptor delta (PPARD or PPARS) (0.6-fold downregulation; Figure $5 \mathrm{~A}$ ) is a member of the peroxisome 


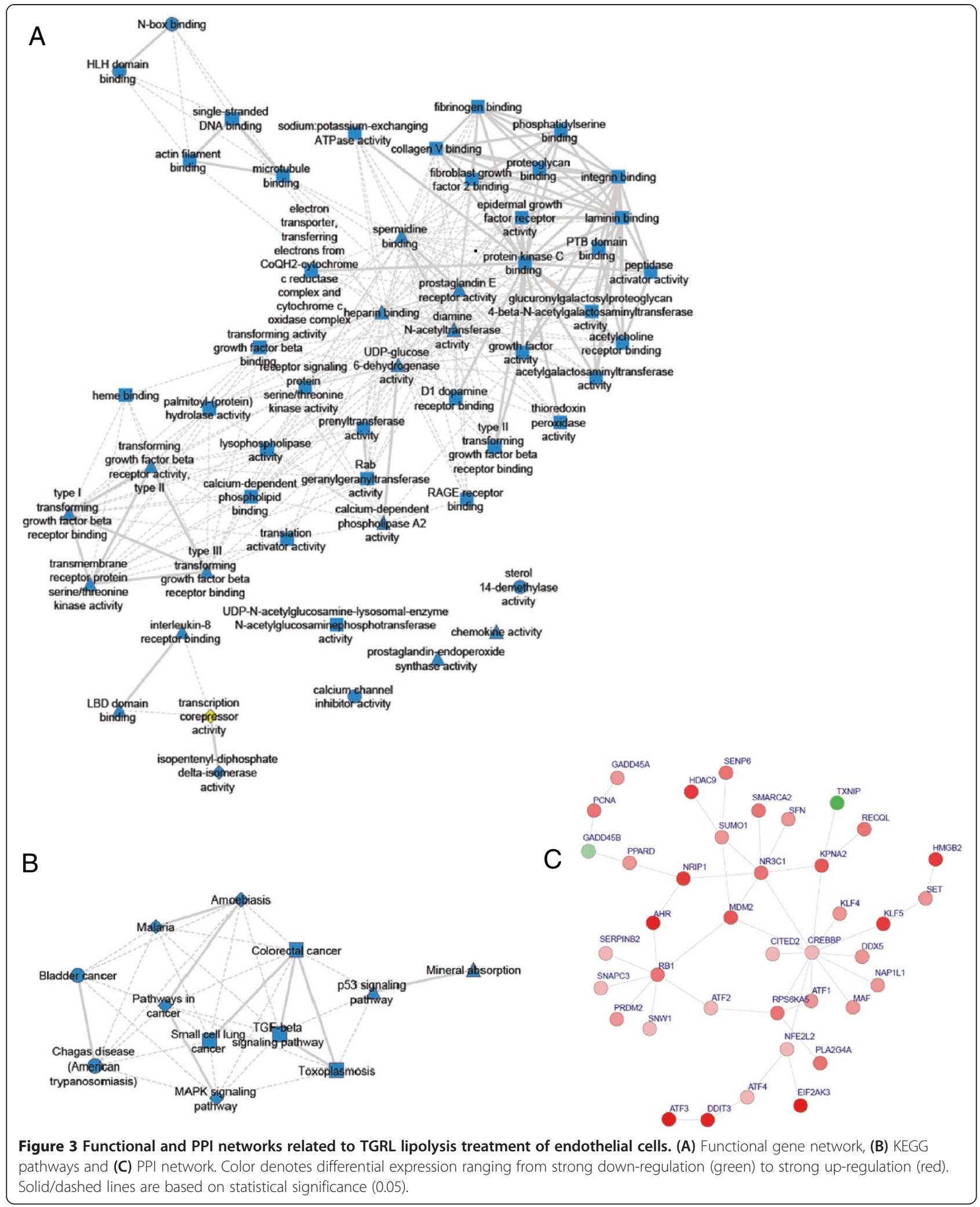

proliferator-activated receptor (PPAR) family. PPARs mediate a variety of biological processes, and may be involved in the development of several chronic diseases, including diabetes, obesity, atherosclerosis, and cancer. PPARs are nuclear receptors regulating the expression of genes involved in lipid and glucose metabolism $[18,19]$. 


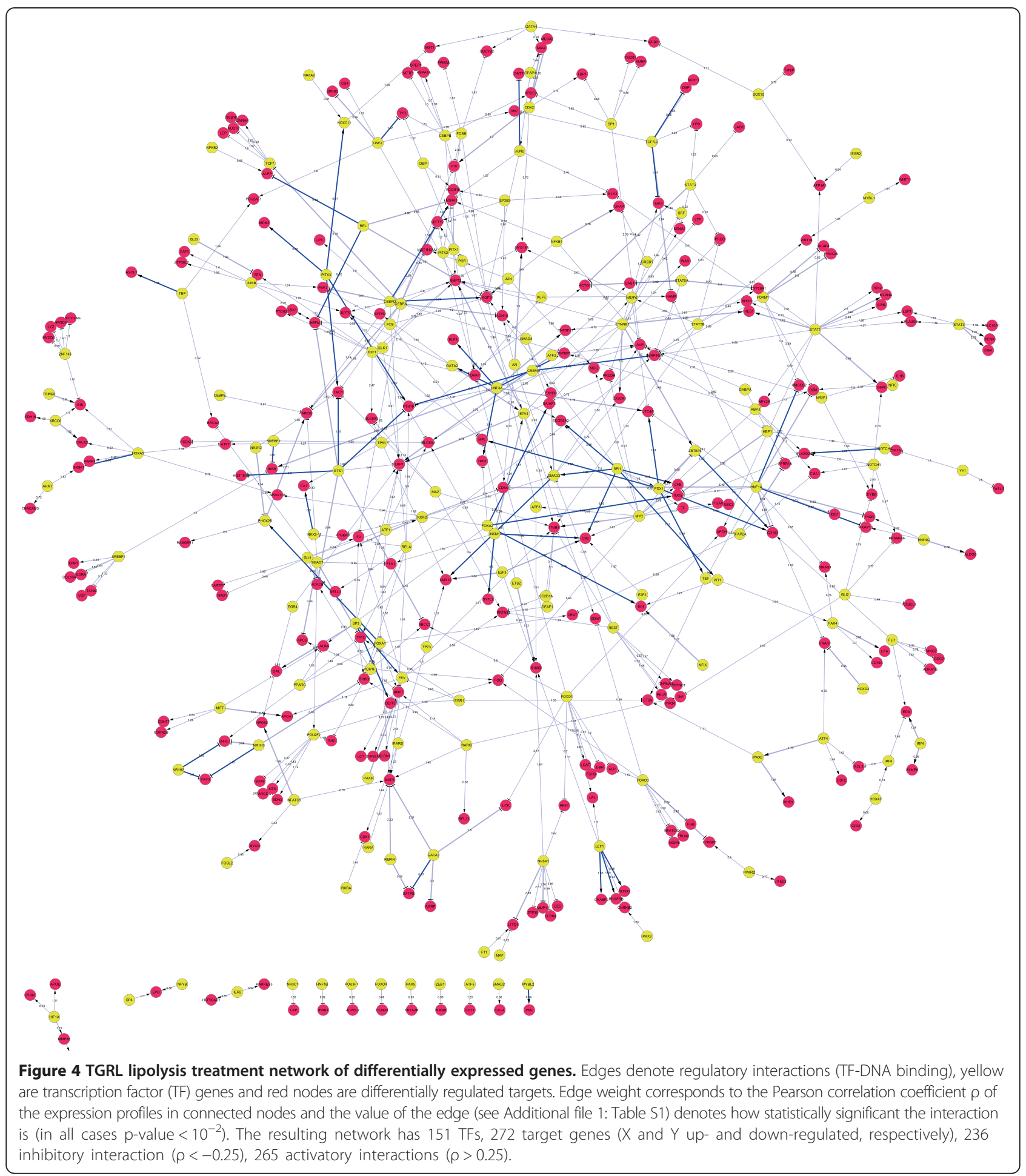

PPARD is an important regulator of fatty acid (FA) metabolism [20]. Increase expression of PPARD has been reported in hepatic steatosis that is induced by oleic acid. Several lines of evidence point to a negative regulatory role for PPAR $\beta / \delta$ in inflammatory responses of the skin. Thus, mice deficient for PPAR $\beta / \delta$ showed an increased inflammatory response to the topical application of O-tetradecanoylphorbol-13-acetate [21].

The Specific protein 3 gene (Sp3; 0.8-fold downregulation; Figure 5A) encodes for transcription factors that regulate transcription by binding to consensus GC- and GT-box regulatory elements in target genes. 


\section{mRNA expression by TGRL Lipolysis Products}

A

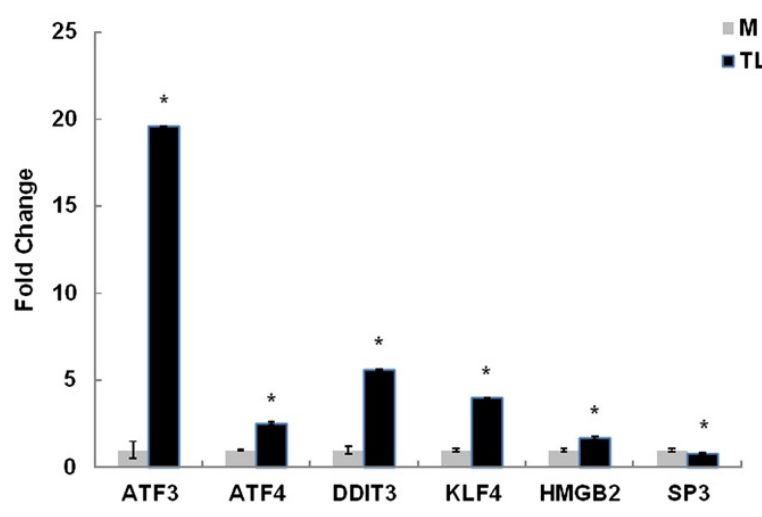

C

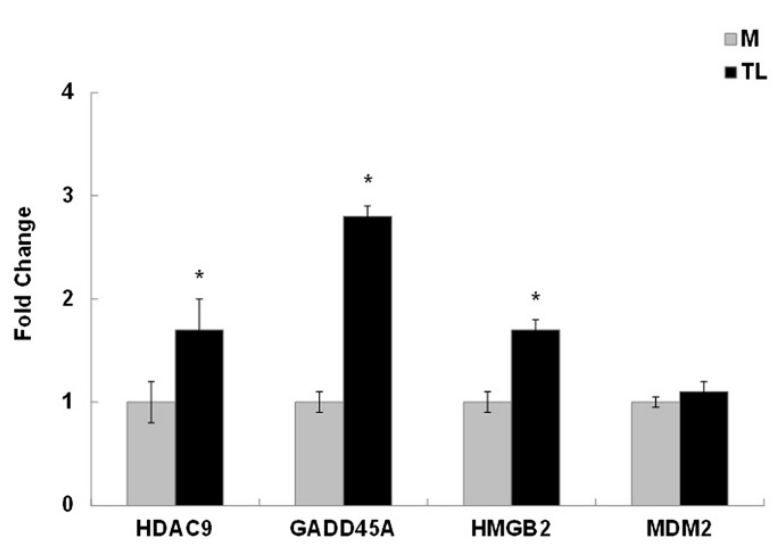

B

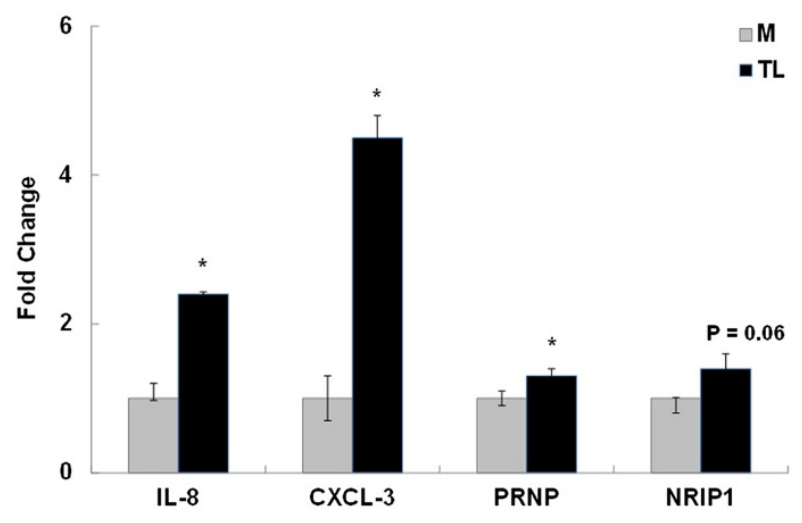

D

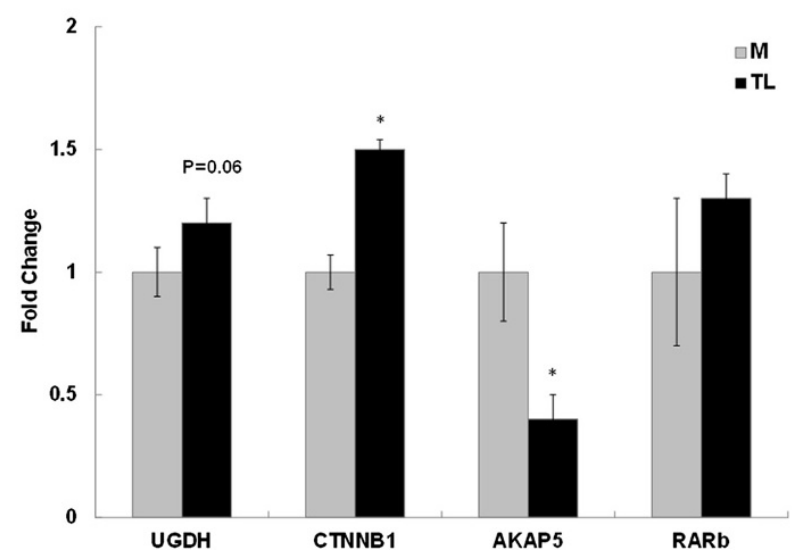

Figure 5 Confirmation of selected genes by qRT-PCR. TGRL lipolysis products (TL) compare to Media (M) alone treatment. Genes related to (A) Transcription factors, (B) Pro-inflammatory Response, (C) Cell cycle and Apoptosis, D) Metabolism and Signalling pathway. HBMVEC were treated with either Media (M) or TGRL lipolysis products (TL) for 3 hr. Microarray analysis: (pooled $n=3$ per GeneChip as compared to TGRL-treated group). For qRT-PCR, the expression of each gene was normalized to that of GAPDH and then fold change was calculated as a ratio of expression after lipolysis products treatment relative to TGRL controls (individual $n=3$ ). An asterisk (*) denotes $p$-value $\leq 0.05$.

Sp3 is an inducer of apoptosis and a marker of tumor aggressiveness [22].

TGRL lipolysis products activate pro-inflammatory factors Interleukin 8 (IL-8 or CXCL8; 2.4-fold up-regulation; Figure $5 B$ ), a member of the CXC chemokine family, is one of the major mediators of inflammatory responses. Chemokine ligand 3 (CXCL3; 4.5-fold up-regulation; Figure $5 \mathrm{~B}$ ), which is known to be induced by oxidized low-density lipoprotein, was also was found to be induced by TGRL lipolysis products. Prion protein (PRNP; 1.3-fold up-regulation; Figure 5B) is a plasma membrane glycosylphosphatidylinositol-anchored glycoprotein that tends to aggregate into rod-like structures. Recently, PRNP has been shown to mediate the toxicity of other pathological protein aggregates, including oligomers of the amyloid $\beta(\mathrm{A} \beta)$ peptide, which are associated with
Alzheimer's disease PRNP [23,24]. It has been reported that PRNP gene contributes the association between the methionine/valine $(\mathrm{M} / \mathrm{V})$ polymorphism and risk of Alzheimer disease [25].

Nuclear receptor interacting protein 1 (NRIP1 also known as RIP140; 1.4-fold up-regulation; Figure 5B), is a nuclear protein that specifically interacts with the hormone-dependent activation domain AF2 of nuclear receptors. NRIP1 is a key regulator that modulates transcriptional activity of a variety of transcription factors, including the estrogen receptor and has an important role in regulating lipid and glucose metabolism. Mice devoid of the co-repressor protein RIP140 are lean, show resistance to high-fat diet-induced obesity and hepatic steatosis, and have increased oxygen consumption [26]. Increased RIP140/ NRIP1 level is associate with inflammation and disorders of lipid and glucose metabolism in diabetic patients [27]. 
SPEG (0.7-fold down-regulation; Figure 5B), also known as aortic preferentially expressed gene-1 (APEG-1), was down-regulated by TGRL lipolysis products. APEG-1 appears to be expressed only in highly differentiated aortic smooth muscle cells (ASMC) in normal vessel walls but it's mRNA was down-regulated in dedifferentiated ASMC in response to vascular injury [28].

\section{TGRL lipolysis product-induced endothelial cell apoptosis} Histone deacetylase 9 (HDAC9; 1.7-fold up-regulation; Figure $5 \mathrm{C}$ ) plays a critical role in transcriptional regulation, cell cycle progression, and developmental events. Histone acetylation/deacetylation alters chromosome structure and affects transcription factor access to DNA. Growth arrest and DNA-damage-inducible, alpha (GADD45A; 2.8-fold up-regulation; Figure $5 \mathrm{C}$ ) and beta (GADD45B) genes are the first well-defined p53 downstream genes. They can be induced by multiple DNA-damaging agents and stressful growth arrest conditions, such as IR and UV radiation, and play important roles in the control of cell cycle checkpoint, DNA repair processes, and signalling transduction. The protein encoded by this gene responds to environmental stresses by mediating activation of the $\mathrm{p} 38 / \mathrm{JNK}$ pathway via MTK1/MEKK4 kinase. No change in GADD45A and loss function of GADD45B suggested that its normal role in the pituitary includes acting as a brake to cell proliferation and survival [29].

Despite their central position in the TGRL-centered PPI network, Mouse double minute 2 homolog (MDM2) and S100 calcium binding protein B (S100B) were not found to be differentially regulated in our samples ( $p$-value $>0.05$; Figure $5 \mathrm{C}$ ). MDM2 is a target gene of the transcription factor tumor protein p53 and also affects the cell cycle, apoptosis, and tumorgenesis through interactions with other proteins. Over expression of this gene results in excessive inactivation of tumor protein $\mathrm{p} 53$, diminishing its tumor suppressor function. S100B is a member of the S100 family of proteins containing 2 EF-hand calciumbinding motifs. S100 proteins are localized in the cytoplasm and/or nucleus of a wide range of cells, and involved in the regulation of a number of cellular processes such as cell cycle progression and differentiation. The altered expressions of this gene have been implicated in several neurological, neoplastic, and other types of diseases, including Alzheimer's disease.

In contrast, the High mobility group box 2 (HMGB2) was up-regulated 1.7-fold by TGRL lipolysis (Figure 5C). HMGB2 gene encodes a member of the non-histone chromosomal high mobility group protein families. In vitro studies have demonstrated that this protein is able to efficiently bend DNA and form DNA circles. HMGB2 is known to stabilize p53 in HeLa cells [30]. Overexpression of HMGB2 in hepatocellular carcinoma is associated with poor prognosis and tumor development [31].

\section{TGRL lipolysis product-induced metabolism and signalling} pathways

UDP-glucose 6-dehydrogenase (UGDH, 1.2-fold upregulation $(\mathrm{p}=0.06)$; Figure $5 \mathrm{D})$, the protein encoded by this gene converts UDP-glucose to UDP-glucuronate and thereby participates in the biosynthesis of glycosaminoglycans such as hyaluronan, chondroitin sulfate, and heparan sulfate. The expression of UGDH is up-regulated by transforming growth factor beta and down-regulated by hypoxia. Catenin (cadherin-associated protein), beta 1 (CTNNB1, 0.8-fold down-regulation; Figure 5D), protein encoded by this gene is part of a complex of proteins that constitute adherens junctions (AJs). AJs are necessary for the creation and maintenance of cell layers by regulating cell growth and adhesion between cells.

The A-kinase anchor protein 5 (AKAP5), a member of the AKAP family and also known as AKAP75 or AKAP79. AKAP5 is predominantly expressed in cerebral cortex and may anchor the PKA protein at postsynaptic densities (PSD) and be involved in the regulation of postsynaptic events. It can bind to the RII-beta regulatory subunit of cAMP-dependent protein kinase (PKA), and also to protein kinase $C$ and the phosphatase calcineurin [32]. AKAP5/AKAP79 is present in the lipid raft of stimulated KG1 cells [33]. Down-regulation of AKAP5 in HBMVEC by TGRL lipolysis products suggests calcineurin-dependent NFAT signalling may involve. Retinoic acid receptor, beta $(\operatorname{RAR} \beta)$, a member of the thyroid-steroid hormone receptor superfamily of nuclear transcriptional regulators was increased 1.3-fold but was not significant. It binds retinoic acid, which mediates cellular signalling in embryonic morphogenesis, and cell growth and differentiation. This protein limits growth of many cell types by regulating gene expression. The mechanism associated with modulation of ERK $1 / 2$ and JNK activation and depends on stimulation of RAR $\beta$ [34].

To gain a better insight on the biological processes, cellular components and molecular functions that are affected by the differentially expressed genes, we performed a functional analysis by using the DAVID toolbox (see Methods) [35,36]. As shown in Figure 6, negative regulation of transcription and biosynthetic processes were highly enriched, as well as the positive regulation of apoptosis and intracellular signalling. Not surprisingly, given the implicated metabolic compounds, membranerelated components and various organelles were the most differentially expressed genes were localized. In agreement with our analysis above, the functional enrichment analysis shows a clear differential regulation of transcriptional units, including transcription factor and cofactor binding, repressor activity and enzyme binding. 


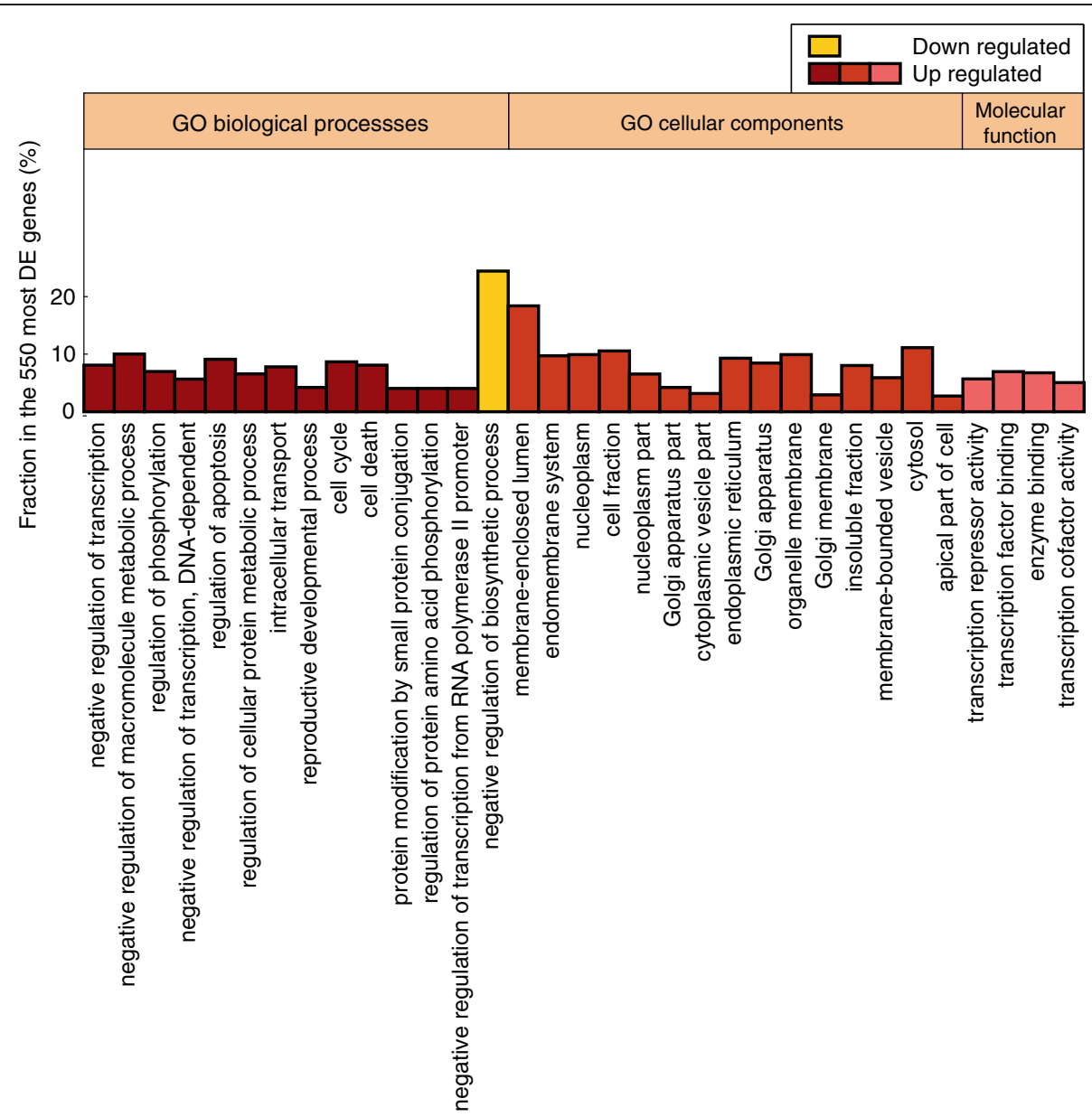

Figure 6 Functional analysis of enriched differentially expressed clusters. Percent of genes that belong in a significantly enriched functional annotation category, out of the 550 top DE genes. Cluster enrichment for GO biological processes, cellular components and molecular function is presented. Functional classes are indexed by increasing p-values: 8e-9 (negative regulation of transcription) to $3 \mathrm{e}-4$ (negative regulation of biosynthetic process) for GO biological processes, 6e-8 (membrane-enclosed lumen) to 3e-3 (apical part of cell) for GO cellular components and 1e-6 (transcription repressor activity) to 3e-4 (transcription cofactor activity) for GO molecular function.

\section{Discussion}

The most significant discovery of this study is the robust and rapid induction of genes encoding transcription factors, inflammation, and apoptosis. More specifically, HBMVEC treated with TGRL lipolysis products encode transcription factor ATF3-related genes in the MAP Kinase pathway associated with AP-1 signalling. This, then, stimulates an array of pro-inflammatory and pro-apoptotic genes that effect endothelial cell injury. ATF3 can be induced by stress and growth factors in mammalian cells, and is thought to play an important role in the cardiovascular and nervous system. However, little is currently known about how the induction of ATF3 is regulated, except that the JNK pathway is involved. Previous studies have shown up-regulation of ATF3 to act as either pro-inflammatory [37] or antiinflammatory [38-40] and it was more recently linked to Alzheimer's disease through a system-level approach [41]. ATF3 belongs to the ATF/cyclic AMP responsive element binding (CREB) family of transcription factors, characterized by a basic region leucine zipper (bZip) motif. The basic region is necessary for binding to the ATF/CRE promoter and the leucine zipper element for homo-and heterodimerization with other bZip proteins to differentially regulate transcription. The dimeric state of ATF3 gives us clues as to the ultimate effects of ATF3 on inflammation. As a homo-dimer, ATF3 acts as a transcriptional regulator inhibiting expression of pro-apoptotic molecules. Alternatively, ATF3 can form a heterodimer with activated c-Jun that enhances transcription of stress response genes [42]. The transcription of ATF3 as a key response gene after treatment for $3 \mathrm{hr}$ with TGRL lipolysis products demonstrated that its induction was essential for the expression of a subset of pro-inflammatory responses.

TGRL lipolysis products-induced signalling pathways involve in mitogen-activated protein (MAP) Kinase, TGF- $\beta$ and p53 signalling. The four major MAP Kinase 
pathways, ERK, JNK, P38, and BMK/ERK5, perform activating phosphorylations of nuclear transcription factors. Of these, ERK has been shown to inhibit ATF3 expression while JNK activates ATF3 through transcriptional regulation [43]. JNK activation also results in phosphorylation of c-Jun, a component with ATF3 of a complex that binds AP-1 responsive promoter regions. As would be expected, c-Jun/AP-1, ATF2, ATF4, ATF6, CREB, Myc, C/EBPB, Erg-1, and other transcription factors have been shown to induce ATF3 expression [44,45].

Our study has shown that increased expression of ATF3 occurs early in response to stress by a mechanism requiring the related bZIP transcriptional regulator ATF4. ATF3 contributes to induction of the apoptosis-inducing protein DDIT3 transcriptional factor in response to TGRL lipolysis products at $3 \mathrm{hr}$. DDIT3, CHOP, or GADD153 protein functions as a dominant-negative inhibitor by forming heterodimers with other C/EBP members, such as C/EBP and is linked to diabetes [13,46,47]. Expression of transcriptional activators ATF4 and CHOP have been reported to be induced during ER stress [48]. Although ATF3, ATF4, and DDIT3 (CHOP) are co-ordinately expressed in response to ER stress, there are differences between these genes regarding the contribution of transcriptional control and the timing of induced expression.

Previous studies have shown up regulation of ATF3 to act as either pro-inflammatory [37] or anti-inflammatory [38-40]. The dimeric state of ATF3 gives us clues as to the ultimate effects of ATF3 on inflammation. As a homodimer, ATF3 acts as a transcriptional regulator inhibiting expression of pro-apoptotic molecules. Alternatively, ATF3 can form a heterodimer with activated c-Jun that enhances transcription of stress response genes [42]. A number of other biological molecules and pathways could contribute to the pro-inflammatory and pro-apoptotic effects of TGRL lipolysis products. In this study, mRNA levels of a number of inflammatory genes were markedly upregulated in TGRL lipolysis products treated HBMVEC. These genes, including IL-8, CXCL-3, PRNP and NRIP1, are important cytokines, which participate in inflammatory cell mobilization and recruitment. Induction of plasma membrane PRNP suggested that PRNP interact with many other proteins and induced vascular inflammation. It was recently shown that unfolded protein response and ATF3 are associated with inflammation response related to atherosclerosis in endothelial cells $[49,50]$. Our previous studies have shown that TGRL lipolysis products activate stress response pathways that induce expression of multiple pro-inflammatory and pro-apoptotic genes leading to endothelial dysfunction [5,51].

TGRL lipolysis products-induced up regulation of HDAC9 suggested vascular inflammation in brain microvascular endothelial cells. Several studies elucidated that the effects of individual HDACs in vasculature. HDAC9 promotes angiogenesis and determines the angiogenic gene expression pattern of endothelial cells [52]. Although HDAC9 gene is significantly associated with large-vessel stroke risk in different population [53], it's actions are not known in microvascular endothelial cells. Our study showed up-regulation of HDAC9, GADD45A and HMGB2 expression regulates cell cycle progression through p53 signalling by TGRL lipolysis products in HBMVEC. Additionally, up-regulation of RAR $\beta$ and JNK, may play a role and further activate vascular inflammation and apoptosis in HBMVEC. Further studies are needed to validate the strength of our system biology analyses and to determine how TGRL lipolysis products regulate physiologically important cell signalling pathways. The marked increased expression of ATF3 suggested that upstream molecules, such as TGF $\beta$ suggest that the mitogenactivated protein kinase pathway activation in HBMVEC by TGRL lipolysis products is mediated through RAR $\beta$.

Lipolysis of TGRL produces an array of remnant lipoprotein particles, fatty acids, phospholipids, diglycerides, and monoglycerides [4]. Any and all of these lipids and lipoproteins could have either pro- or anti-inflammatory effects on the endothelial cells although our previous work suggest that it is the fatty acids that are the primary mediators of endothelial cell injury at high physiological or pathophysiological concentrations [54-56]. However, the broad activation of transcription factors and proinflammatory genes suggests that other components of TGRL lipolysis products also could be playing a part in addition to fatty acids.

The peak elevation in blood TGRL is about 3-4 hours after a meal and blood triglycerides can rise 0.3-fold to many-fold higher during the postprandial period. Lipolysis of TGRL by endothelial cell-associated lipoprotein lipase likewise peaks in the postprandial period thus producing more endothelial cell injury or lipotoxicity as a result of the release of TGRL lipolysis products directly on the endothelial cells. Rather than low-grade, chronic injury, endothelial cells are injured repetitively over the course of a day, which could be a more pathological form of injury.

The precise pathogenetic mechanisms associated with lipotoxic neurovasclular inflammation remain to be elucidated. These experiments confirm the results of our previous work showing that high physiological to pathophysiological concentrations of TGRL lipolysis products induce brain microvascular lipotoxicity resulting in endothelial cell injury and apoptosis. These effects could alter blood-brain barrier integrity allowing not only potentially injurious lipids access to the brain, but also enabling thrombosis to occur on the injured brain endothelium causing brain microinfarctions. Thus, neurovascular lipotoxicity could induce brain injury and resulting decline in cognitive function. 
Our microarray data and system biology analysis give us possible clues involving cell signalling pathways in HBMVEC treated with TGRL lipolysis products. The systems biology approach that was taken in this study allows to identify statistically significant associations by using a consensus analysis of 4 different methods, as well as looking simultaneously at the transcriptional, protein-protein interaction and gene ontology networks. Using a supervised interaction inference methodology that exploits the experimentally identified interactions that are known so far, is likely to increase the true positive rate of our analysis when compared to unsupervised methods. An extension to this work is looking at how information propagates through the combined gene regulatory and signal transduction networks by applied informationbased methodologies [57-60]. Our methodology will benefit substantially from increasing the number of biological replicates and the use of next-generation sequencing technologies (RNA-Seq) with appropriate coverage and depth, as in this study, mRNA of the control and treated groups were pooled ( $\mathrm{n}=3$ ), while the confirmation by RT-PCR was done on individual samples $(n=3)$ in each of the groups. Despite this limitation, we were able to confirm approximately $50 \%$ of the genes that were predicted by our computational analyses to be implicated in this phenomenon.

\section{Conclusions}

Our systems biology approach demonstrated a robust and rapid induction of genes encoding transcription factors, inflammation, and apoptosis. Specifically, HBMVEC treated with TGRL lipolysis products encode transcription factor ATF3-related genes in the MAP kinase pathway associated with AP-1 signalling, which stimulates an array of pro-inflammatory and pro-apoptotic genes that effect endothelial cell injury. These experiments confirm the results of our previous work and demonstrate the complex, parallel, and multifaceted aspects of cell signalling that high physiological to pathophysiological concentrations of TGRL lipolysis products induce in brain microvascular lipotoxicity resulting in endothelial cell injury and apoptosis. Future studies are needed to show if these neurovascular pathophysiological processes are associated with the development of cognitive impairment.

\section{Methods}

Human TGRL isolation: Postprandial blood samples were obtained $3.5 \mathrm{~h}$ after consumption of a moderately high-fat meal, which generally corresponds to the peak elevation in plasma triglyceride concentrations. Triglyceride-rich lipoproteins (TGRL) were isolated from human plasma at a density of less than $1.0063 \mathrm{~g} / \mathrm{mL}$ following an $18 \mathrm{~h}$ centrifugation at 40,000 rpm in a SW41 Ti swinging bucket rotor (Beckman Coulter, Sunnyvale, CA) held at $14^{\circ} \mathrm{C}$ within a Beckman L8-70 M (Beckman) ultracentrifuge.
The top fraction (TGRL) was collected and dialyzed in Spectrapor membrane tubing (mol wt cut off 3,500; Spectrum Medical Industries, Los Angeles, CA) at $4^{\circ} \mathrm{C}$ overnight against a saline solution containing $0.01 \%$ EDTA. This protocol was approved by the Human Subjects Review Committee at the University of California Davis.

\section{Cell culture and lipid treatments}

Human brain microvascular endothelial cells (HBMVEC) (passage 6, Cell Systems, Kirkland, WA) were cultured in CSC Complete Medium which includes 10\% serum (4Z0-500) (Cell Systems, Kirkland, WA) under an atmosphere of $5 \% \mathrm{CO} 2: 95 \%$ air at $37^{\circ} \mathrm{C}$. Lipoprotein lipase (LpL) (L2254) was purchased from Sigma, St. Louis, MO. 3' IVT Express Kit was purchased from Affymetrix, Santa Clara, CA. Cells were exposed for $3 \mathrm{hr}$ to the following conditions, media, TGRL $(150 \mathrm{mg} / \mathrm{dL}=1.5 \mathrm{mg} / \mathrm{mL}$ ), lipoprotein lipase (LpL) $(2 \mathrm{U} / \mathrm{mL}$ ), and TGRL lipolysis product (TGRL $(150 \mathrm{mg} / \mathrm{dL})+\mathrm{LpL}(2 \mathrm{U} / \mathrm{mL}))$. The final concentration of TGRL, LpL and TGRL lipolysis products were diluted in media and pre-incubated for 30 minute at $37^{\circ} \mathrm{C}$ prior to application. After incubation, cells were washed with cold PBS and further process for RNA extraction.

\section{RNA extraction and synthesis of biotin-labeled RNA}

Total RNA was extracted from Media, LpL, TGRL, and TGRL lipolysis products in HBMVEC in 6-well plate using RNeasy Mini Kit (Qiagen) including the DNA digestion step as described by the manufacturer. Microarray experiments were performed with pooled RNA isolates from each treatment group.

\section{GeneChip analyses}

GeneChip analyses of the pooled total RNA samples $(\mathrm{n}=3$ per group for Media, LpL, TGRL, and TGRL lipolysis products treatments) were performed as previously described [5,61]. A $200 \mathrm{ng}$ aliquot of total RNA from each pooled sample was reverse-transcribed, followed by aRNA Amplification, reverse transcription to synthesize firststrand cDNA, second-strand cDNA Synthesis, in vitro transcription to synthesize labeled aRNA, purification and fragmentation of aRNA as described in the Affymetrix 3' IVT Express Kit protocol (Affymetrix, Santa Clara, CA). The fragmentation of labeled aRNA samples were hybridized to Human Genome U133A 2.0 Array high-density oligonucleotide arrays with $\sim 22,000$ probe sets representing 14,500 well-characterized human genes (Affymetrix). The hybridization, washing, labeling, and scanning of the GeneChips were performed as described in the Affymetrix protocols by the Microarray Core Facility in the UC Davis Genome and Biomedical Sciences Facility. The microarray dataset was deposited to Gene Expression Omnibus (GEO) with accession ID GSE57526. 


\section{Validation of changes in mRNA expression by quantitative RT-PCR (qRT-PCR)}

Since GeneChip analysis was done on pooled samples from each experimental group, confirming qRT-PCR analyses were performed on individual aliquots of total RNA samples from each treatment replicate. The purpose of these analyses was to evaluate the reliability of GeneChip data and develop statistical data to validate the changes suggested by the GeneChip assay of pooled RNA samples as our previous study as two assays may not match quantitatively but they always match qualitatively. Two analytical procedures may contribute to these discrepancies. 1) Total RNA samples used for the PCR assay are different from those used for the microarray assays. 2) The method of hybridization and detection for the two assays are different; the microarray assay utilizes hybridization of fragmented cRNA generated by Affymetrix protocols, whereas the RT-PCR utilizes amplification of DNA fragments using specific primer sets designed by a different method.

An aliquot equivalent to $5 \mu \mathrm{g}$ of total RNA extracted from each sample was reverse-transcribed to obtain cDNA in a final volume of $20 \mu \mathrm{l}$ solution consisting of buffer, oligo-dT primer, DTT, dNTPs, and SuperscriptIII reverse transcriptase (Invitrogen). RT-PCR with SYBR as fluorescent reporter was used to quantify the expression of selected genes identified by GeneChip analysis. Specific primers (Additional file 1: Table S1) were designed with Primer Express 1.0 software (Applied Biosystems) using the gene sequences obtained from Affymetrix Probeset IDs. Reactions were carried out in 384-well optical plates containing $25 \mathrm{ng}$ RNA in each well. The quantity of applied RNA was normalized by simultaneously amplifying cDNA samples with glyceraldehyde-3-phosphate dehydrogenase (GAPDH)-specific primers. The transcript levels were measured by real-time RT-PCR using the ABI Vii7 Sequence detection system (PE Applied Biosystems, Foster City, CA). The PCR amplification parameters were: initial denaturation step at $95^{\circ} \mathrm{C}$ for 10 min followed by 40 cycles, each at $95^{\circ} \mathrm{C}$ for $15 \mathrm{~s}$ (melting) and $60^{\circ} \mathrm{C}$ for $1 \mathrm{~min}$ (annealing and extension). A comparative threshold cycle (Ct) method [62] was used to calculate relative changes in gene expression determined from real-time quantitative PCR experiments [Applied Biosystems user bulletin no. 2 (P/N4303859)]. The $\mathrm{Ct}$, which correlates inversely with the target mRNA levels, was measured as the cycle number at which the SYBR Green emission increases above a preset threshold level. The specific mRNA transcripts were expressed as fold difference in the expression of the specific mRNAs in RNA samples from the TGRL lipolysis-treated cells compared with those from the control-treated cells.

\section{Analysis and differential expression}

In conjunction with the AFFY Bioconductor package [63], we used several methods to extract the expression profiles and normalize the data. These include the BGX8 and mmgMOS [64] algorithms that take into account both perfect-match (PM) and mismatch (MM) probes to increase the statistical significance of the findings. To identify the differential expression (DE) profiles among the four conditions, we used the PUMA [65], PPLR [66] and IPPRL [67] packages. In addition we considered the popular MAS5 and RMA methods, although the later do not take into account the MM probes, which decrease the confidence level of the results.

\section{Functional and PPI networks}

We used probabilistic Bayesian methods via an open-source package that uses Gene Ontology (GO) and KEGG annotations to create a functional gene network from microarray expression profiling data [68]. We integrated the expression-derived relationships with the known protein-protein interaction (PPI) network that was extracted with BIONET Bioconductor package [6] and by using an established base network (Interactome Library [7]). We then used the DAVID (The Database for Annotation, Visualization and Integrated Discovery) tool [35,36] to extract functional annotation terms enriched in the top 550 differentially expressed genes with respect to the control. We analyzed up- and down- regulated genes independently. Gene Ontology (GO) terms such as cellular components, molecular functions and biological processes were considered. We select the number of significant functional annotation terms produced from DAVID for each gene set based on the following criteria: (a) we only consider terms which include at least $2.5 \%$ of the gene set and (b) we consider terms to be statistically significant if they have a Benjamini-adjusted p-value less than 0.05 . Highly related annotation terms $(k>0.9)$ are grouped by the term with the most genes and by their parent terms. Only terms in the GO FAT category are selected in order to filter out the very broad ones (Figure 6).

\section{Gene regulatory network inference}

After literature curation, we created a dataset of all known transcription factor (TF)-gene interactions in human cells, with more than 4,000 experimentally validated interactions. Microvascular endothelial cell specific experiments [69-75] account for less than 5\% of the connections we currently use in the training phase and are not adequate for training, as this would radically limit the scope of the method in finding new connections than the already established ones. Thus, the whole set of interactions was used as the training set for supervised learning through SIRENE [8], which uses support vector machines (SVM) [76] to classify genes to specific transcription factor bins, based on how related their expression pattern is to other genes that are known to be regulated by a specific TF. The resulting condition-specific Gene Regulatory Network 
(GRN) associated with TGRL lipolysis treatment was further enhanced by the regulatory predictions derived (repression/activation) by using Pearson correlation coefficient (PCC) on the expression profiles of the participants in each of the inferred connections regulatortarget pair.

\section{Ethics}

No human subjects were used for this study.

\section{Additional file}

Additional file 1: Supporting material. Table S1. Primer Sequences.

\section{Competing interests}

The authors declare that they have no competing interests.

\section{Authors' contributions}

JCR and HHA initiated the study. HHA prepared the samples for analysis of microarray and the quantitative RT-PCR. AT performed the bioinformatics analysis. IT supervised all aspects of the computational analysis. HHA, NT, JCR and IT wrote the manuscript. All authors read and approved the final manuscript.

\section{Acknowledgements}

We would like to thank the members of the I.T. and J.C.R. labs for the helpful comments and discussions during the course of this study.

\section{Sources of funding}

This work was supported by the NIH-HL55667, NIH-NIA AG039094 to J.C.R. CITRIS award 2469085 and CTSC NIH-UL1-TR000002 to I.T.

\section{Author details}

'Division of Cardiovascular Medicine, Department of Internal Medicine, University of California, Davis, CA 95616, USA. ${ }^{2}$ UC Davis Genome Center, University of California, Davis, CA 95616, USA. ${ }^{3}$ Department of Computer Science, University of California, Davis, CA 95616, USA.

Received: 27 March 2014 Accepted: 23 June 2014 Published: 4 July 2014

\section{References}

1. Hurd MD, Martorell P, Langa KM: Monetary costs of dementia in the United States. N Engl J Med 2013, 369(5):489-490.

2. Pallebage-Gamarallage MM, Lam V, Takechi R, Galloway S, Mamo JC: A diet enriched in docosahexanoic acid exacerbates brain parenchymal extravasation of apo B lipoproteins induced by chronic ingestion of saturated fats. Int J Vasc Med 2012, 2012:647689.

3. Altman R, Rutledge JC: The vascular contribution to Alzheimer's disease. Clin Sci (Lond) 2010, 119(10):407-421.

4. Wang L, Gill R, Pedersen TL, Higgins LJ, Newman JW, Rutledge JC: Triglyceride-rich lipoprotein lipolysis releases neutral and oxidized FFAs that induce endothelial cell inflammation. J Lipid Res 2009, 50(2):204-213.

5. Aung HH, Lame MW, Gohil K, An Cl, Wilson DW, Rutledge JC: Induction of ATF3 gene network by triglyceride-rich lipoprotein lipolysis products increases vascular apoptosis and inflammation. Arterioscler Thromb Vasc Biol 2013, 33(9):2088-2096.

6. Beisser D, Klau GW, Dandekar T, Muller T, Dittrich MT: BioNet: an R-package for the functional analysis of biological networks. Bioinformatics 2010, 26(8):1129-1130.

7. Dittrich MT, Klau GW, Rosenwald A, Dandekar T, Muller T: Identifying functional modules in protein-protein interaction networks: an integrated exact approach. Bioinformatics 2008, 24(13):i223-i231.

8. Mordelet F, Vert JP: SIRENE: supervised inference of regulatory networks. Bioinformatics 2008, 24(16):i76-i82.
9. Hai T, Wolford CC, Chang YS: ATF3, a hub of the cellular adaptive-response network, in the pathogenesis of diseases: is modulation of inflammation a unifying component? Gene Expr 2010, 15(1):1-11.

10. Gupta S, Campbell D, Derijard B, Davis RJ: Transcription factor ATF2 regulation by the JNK signal transduction pathway. Science 1995, 267(5196):389-393.

11. Derijard B, Hibi M, Wu IH, Barrett T, Su B, Deng T, Karin M, Davis RJ: JNK1: a protein kinase stimulated by UV light and Ha-Ras that binds and phosphorylates the c-Jun activation domain. Cell 1994, 76(6):1025-1037.

12. Pombo CM, Bonventre JV, Avruch J, Woodgett JR, Kyriakis JM, Force T: The stress-activated protein kinases are major c-Jun amino-terminal kinases activated by ischemia and reperfusion. J Biol Chem 1994, 269(42):26546-26551.

13. Chen BP, Wolfgang CD, Hai T: Analysis of ATF3, a transcription factor induced by physiological stresses and modulated by gadd153/Chop 10 . Mol Cell Biol 1996, 16(3):1157-1168.

14. Chen Y, Wang JJ, Li J, Hosoya KI, Ratan R, Townes T, Zhang SX: Activating transcription factor 4 mediates hyperglycaemia-induced endothelial inflammation and retinal vascular leakage through activation of STAT3 in a mouse model of type 1 diabetes. Diabetologia 2012, 55(9):2533-2545.

15. Zhou B, Liu Y, Kahn M, Ann DK, Han A, Wang H, Nguyen C, Flodby P, Zhong Q, Krishnaveni MS, Liebler JM, Minoo P, Crandall ED, Borok Z: Interactions between beta-catenin and transforming growth factor-beta signaling pathways mediate epithelial-mesenchymal transition and are dependent on the transcriptional co-activator CAMP-response element-binding protein (CREB)-binding protein (CBP). J Biol Chem 2012, 287(10):7026-7038.

16. Zhou G, Hamik A, Nayak L, Tian H, Shi H, Lu Y, Sharma N, Liao X, Hale A, Boerboom L, Feaver RE, Gao H, Desai A, Schmaier A, Gerson SL, Wang Y, Atkins GB, Blackman BR, Simon DI, Jain MK: Endothelial Kruppel-like factor 4 protects against atherothrombosis in mice. $J$ Clin Invest 2012, 122(12):4727-4731.

17. Hamik A, Lin Z, Kumar A, Balcells M, Sinha S, Katz J, Feinberg MW, Gerzsten RE, Edelman ER, Jain MK: Kruppel-like factor 4 regulates endothelial inflammation. J Biol Chem 2007, 282(18):13769-13779.

18. Yang Q, Li Y: Roles of PPARs on regulating myocardial energy and lipid homeostasis. J Mol Med (Berl) 2007, 85(7):697-706.

19. Derosa G, Maffioli P: Peroxisome proliferator-activated receptor-gamma (PPAR-gamma) agonists on glycemic control, lipid profile and cardiovascular risk. Curr Mol Pharmacol 2012, 5(2):272-281.

20. Xu HE, Lambert MH, Montana VG, Parks DJ, Blanchard SG, Brown PJ, Sternbach DD, Lehmann JM, Wisely GB, Willson TM, Kliewer SA, Milburn MV: Molecular recognition of fatty acids by peroxisome proliferator-activated receptors. Mol Cell 1999, 3(3):397-403.

21. Peters JM, Lee SS, Li W, Ward JM, Gavrilova O, Everett C, Reitman ML, Hudson LD, Gonzalez FJ: Growth, adipose, brain, and skin alterations resulting from targeted disruption of the mouse peroxisome proliferator-activated receptor beta(delta). Mol Cell Biol 2000, 20(14):5119-5128.

22. Essafi-Benkhadir K, Grosso S, Puissant A, Robert G, Essafi M, Deckert M, Chamorey $E$, Dassonville $O$, Milano $G$, Auberger $P$, Pagès $G$ : Dual role of Sp3 transcription factor as an inducer of apoptosis and a marker of tumour aggressiveness. PLoS One 2009, 4(2):e4478.

23. Rushworth JV, Hooper NM: Lipid rafts: linking Alzheimer's amyloid-beta production, aggregation, and toxicity at neuronal membranes. Int J Alzheimers Dis 2010, 2011:603052.

24. Chen S, Yadav SP, Surewicz WK: Interaction between human prion protein and amyloid-beta (Abeta) oligomers: role OF N-terminal residues. J Biol Chem 2010, 285(34):26377-26383.

25. He J, Li X, Yang J, Huang J, Fu X, Zhang Y, Fan H: The association between the methionine/valine (M/V) polymorphism (rs 1799990) in the PRNP gene and the risk of Alzheimer disease: an update by meta-analysis. J Neurol Sci 2013, 326(1-2):89-95.

26. Rosell $M$, Jones MC, Parker MG: Role of nuclear receptor corepressor RIP140 in metabolic syndrome. Biochim Biophys Acta 2011, 1812(8):919-928.

27. Xue J, Zhao H, Shang G, Zou R, Dai Z, Zhou D, Huang Q, Xu Y: RIP140 is associated with subclinical inflammation in type 2 diabetic patients. Exp Clin Endocrinol Diabetes 2013, 121(1):37-42.

28. Hsieh CM, Yoshizumi M, Endege WO, Kho CJ, Jain MK, Kashiki S, Delos Santos R, Lee WS, Perrella MA, Lee ME: APEG-1, a novel gene preferentially expressed in aortic smooth muscle cells, is down-regulated by vascular injury. J Biol Chem 1996, 271(29):17354-17359.

29. Michaelis KA, Knox AJ, Xu M, Kiseljak-Vassiliades K, Edwards MG, Geraci M, Kleinschmidt-DeMasters BK, Lillehei KO, Wierman ME: Identification of growth 
arrest and DNA-damage-inducible gene beta (GADD45beta) as a novel tumor suppressor in pituitary gonadotrope tumors. Endocrinology 2011, 152(10):3603-3613.

30. Lee D, Kwon JH, Kim EH, Kim ES, Choi KY: HMGB2 stabilizes p53 by interfering with E6/E6AP-mediated p53 degradation in human papillomavirus-positive HeLa cells. Cancer Lett 2010, 292(1):125-132.

31. Kwon JH, Kim J, Park JY, Hong SM, Park CW, Hong SJ, Park SY, Choi YJ, Do IG, Joh JW, Kim DS, Choi KY: Overexpression of high-mobility group box 2 is associated with tumor aggressiveness and prognosis of hepatocellular carcinoma. Clin Cancer Res 2010, 16(22):5511-5521.

32. Altier C, Dubel SJ, Barrere C, Jarvis SE, Stotz SC, Scott JD, Nargeot J, Zamponi GW, Bourinet E: AKAP79 modulation of L-type channels involves disruption of intramolecular interactions in the CaV1.2 subunit. Channels (Austin) 2012, 6(3):157-165.

33. Schillace RV, Miller CL, Carr DW: AKAPs in lipid rafts are required for optimal antigen presentation by dendritic cells. Immunol Cell Biol 2011, 89(5):650-658.

34. Huo L, Cui D, Yang X, Gao Z, Trier K, Zeng J: All-trans retinoic acid modulates mitogen-activated protein kinase pathway activation in human scleral fibroblasts through retinoic acid receptor beta. Mol Vis 2013, 19:1795-1803.

35. Huang DW, Sherman BT, Lempicki RA: Systematic and integrative analysis of large gene lists using DAVID bioinformatics resources. Nat Protoc 2009, 4(1):44-57.

36. Huang DW, Sherman BT, Lempicki RA: Bioinformatics enrichment tools: paths toward the comprehensive functional analysis of large gene lists. Nucleic Acids Res 2009, 37(1):1-13.

37. Zmuda EJ, Viapiano M, Grey ST, Hadley G, Garcia-Ocana A, Hai T: Deficiency of Atf3, an adaptive-response gene, protects islets and ameliorates inflammation in a syngeneic mouse transplantation model. Diabetologia 2010, 53(7):1438-1450.

38. Khuu CH, Barrozo RM, Hai T, Weinstein SL: Activating transcription factor 3 (ATF3) represses the expression of CCL4 in murine macrophages. Mol Immunol 2007, 44(7):1598-1605.

39. Gilchrist M, Thorsson V, Li B, Rust AG, Korb M, Roach JC, Kennedy K, Hai T, Bolouri $\mathrm{H}$, Aderem A: Systems biology approaches identify ATF3 as a negative regulator of toll-like receptor 4. Nature 2006, 441(7090):173-178.

40. Whitmore MM, Iparraguirre A, Kubelka L, Weninger W, Hai T, Williams BR: Negative regulation of TLR-signaling pathways by activating transcription factor-3. J Immuno/ 2007, 179(6):3622-3630.

41. Zhang B, Gaiteri C, Bodea LG, Wang Z, McElwee J, Podtelezhnikov AA, Zhang C, Xie T, Tran L, Dobrin R, Fluder E, Clurman B, Melquist S, Narayanan M, Suver C, Shah H, Mahajan M, Gillis T, Mysore J, MacDonald ME, Lamb JR, Bennett DA, Molony C, Stone DJ, Gudnason V, Myers AJ, Schadt EE, Neumann H, Zhu J, Emilsson V: Integrated systems approach identifies genetic nodes and networks in late-onset Alzheimer's disease. Cell 2013, 153(3):707-720.

42. Hsu JC, Laz T, Mohn KL, Taub R: Identification of LRF-1, a leucine-zipper protein that is rapidly and highly induced in regenerating liver. Proc Natl Acad Sci U S A 1991, 88(9):3511-3515.

43. Inoue K, Zama T, Kamimoto T, Aoki R, Ikeda Y, Kimura H, Hagiwara M: TNFalpha-induced ATF3 expression is bidirectionally regulated by the JNK and ERK pathways in vascular endothelial cells. Genes Cells 2004, 9(1):59-70.

44. Tamura K, Hua B, Adachi S, Guney I, Kawauchi J, Morioka M, Tamamori-Adachi M, Tanaka Y, Nakabeppu Y, Sunamori M, Sedivy JM, Kitajima S: Stress response gene ATF3 is a target of c-myc in serum-induced cell proliferation. EMBO J 2005, 24(14):2590-2601.

45. Huo JS, McEachin RC, Cui TX, Duggal NK, Hai T, States DJ, Schwartz J: Profiles of growth hormone (GH)-regulated genes reveal time-dependent responses and identify a mechanism for regulation of activating transcription factor 3 by GH. J Biol Chem 2006, 281(7):4132-4141.

46. Fawcett TW, Martindale JL, Guyton KZ, Hai T, Holbrook NJ: Complexes containing activating transcription factor (ATF)/CAMP-responsive-element-binding protein (CREB) interact with the CCAAT/enhancer-binding protein (C/EBP)-ATF composite site to regulate Gadd153 expression during the stress response. Biochem J 1999, 339(Pt 1):135-141.

47. Hai T, Wolfgang CD, Marsee DK, Allen AE, Sivaprasad U: ATF3 and stress responses. Gene Expr 1999, 7(4-6):321-335.

48. Harding HP, Novoa I, Zhang Y, Zeng H, Wek R, Schapira M, Ron D: Regulated translation initiation controls stress-induced gene expression in mammalian cells. Mol Cell 2000, 6(5):1099-1108.

49. Gargalovic PS, Imura M, Zhang B, Gharavi NM, Clark MJ, Pagnon J, Yang WP, He A, Truong A, Patel S, Nelson SF, Horvath S, Berliner JA, Kirchgessner TG,
Lusis AJ: Identification of inflammatory gene modules based on variations of human endothelial cell responses to oxidized lipids. Proc Natl Acad Sci U S A 2006, 22(103(34)):12741-12746.

50. Gargalovic PS, Gharavi NM, Clark MJ, Pagnon J, Yang WP, He A, Truong A, Baruch-Oren T, Berliner JA, Kirchgessner TG, Lusis AJ: The unfolded protein response is an important regulator of inflammatory genes in endothelial cells. Arterioscler Thromb Vasc Biol 2006, 26(11):2490-2496.

51. Kálai T, Petrlova J, Balog M, Aung HH, Voss JC, Hideg K: Synthesis and study of 2-amino-7-bromofluorenes modified with nitroxides and their precursors as dual anti-amyloid and antioxidant active compounds. Eur J Med Chem 2011, 46(4):1348-1355.

52. Kaluza D, Kroll J, Gesierich S, Manavski Y, Boeckel JN, Doebele C, Zelent A, Rossig L, Zeiher AM, Augustin HG, Urbich C, Dimmeler S: Histone deacetylase 9 promotes angiogenesis by targeting the antiangiogenic microRNA-17-92 cluster in endothelial cells. Arterioscler Thromb Vasc Biol 2013, 33(3):533-543.

53. Bellenguez C, Bevan S, Gschwendtner A, Spencer CC, Burgess Al, Pirinen M, Jackson CA, Traylor M, Strange A, Su Z, Band G, Syme PD, Malik R, Pera J, Norrving B, Lemmens R, Freeman C, Schanz R, James T, Poole D, Murphy L, Segal H, Cortellini L, Cheng YC, Woo D, Nalls MA, Müller-Myhsok B, Meisinger $C$, Seedorf U, Ross-Adams $H$, et al: Genome-wide association study identifies a variant in HDAC9 associated with large vessel ischemic stroke. Nat Genet 2012, 44(3):328-333.

54. Norata GD, Grigore L, Raselli S, Seccomandi PM, Hamsten A, Maggi FM, Eriksson P, Catapano AL: Triglyceride-rich lipoproteins from hypertriglyceridemic subjects induce a pro-inflammatory response in the endothelium: Molecular mechanisms and gene expression studies. J Mol Cell Cardiol 2006, 40(4):484-494

55. Norata GD, Grigore L, Raselli S, Redaelli L, Hamsten A, Maggi F, Eriksson P, Catapano AL: Post-prandial endothelial dysfunction in hypertriglyceridemic subjects: molecular mechanisms and gene expression studies. Atherosclerosis 2007, 193(2):321-327.

56. Ting HJ, Stice JP, Schaff UY, Hui DY, Rutledge JC, Knowlton AA, Passerini AG, Simon SI: Triglyceride-rich lipoproteins prime aortic endothelium for an enhanced inflammatory response to tumor necrosis factor-alpha. Circ Res 2007, 100(3):381-390.

57. Pavlogiannis A, Mozhayskiy V, Tagkopoulos I: A flood-based information flow analysis and network minimization method for gene regulatory networks. BMC Bioinformatics 2013, 14:137.

58. Gultepe E, Green JP, Nguyen H, Adams J, Albertson T, Tagkopoulos I: From vital signs to clinical outcomes for patients with sepsis: a machine learning basis for a clinical decision support system. J Am Med Inform Assoc 2014, 21(2):315-325.

59. Liang Y, Wu H, Lei R, Chong RA, Wei Y, Lu X, Tagkopoulos I, Kung SY, Yang Q, Hu G, Kang Y: Transcriptional network analysis identifies BACH1 as a master regulator of breast cancer bone metastasis. J Biol Chem 2012, 287(40):33533-33544.

60. Tagkopoulos I, Slavov N, Kung SY: Multi-Class Biclustering and Classification Based on Modeling of Gene Regulatory Networks. In BIBE2005, Proceedings of the 5th IEEE Symposium on Bioengineering and Bioinformatics: 2005. Minneapolis, Minnesota; 2005:89-96.

61. Aung HH, Lame MW, Gohil K, He G, Denison MS, Rutledge JC, Wilson DW: Comparative gene responses to collected ambient particles in vitro: endothelial responses. Physiol Genomics 2011, 43(15):917-929.

62. Livak KJ, Schmittgen TD: Analysis of relative gene expression data using real-time quantitative PCR and the 2(-Delta Delta C(T)) Method. Methods 2001, 25(4):402-408.

63. Gautier L, Cope L, Bolstad BM, Irizarry RA: affy-analysis of Affymetrix GeneChip data at the probe level. Bioinformatics 2004 20(3):307-315

64. Liu X, Milo M, Lawrence ND, Rattray M: A tractable probabilistic model for Affymetrix probe-level analysis across multiple chips. Bioinformatics 2005, 21(18):3637-3644.

65. Pearson RD, Liu X, Sanguinetti G, Milo M, Lawrence ND, Rattray M: puma: a Bioconductor package for propagating uncertainty in microarray analysis. BMC Bioinformatics 2009, 10:211.

66. Liu X, Milo M, Lawrence ND, Rattray M: Probe-level measurement error improves accuracy in detecting differential gene expression. Bioinformatics 2006, 22(17):2107-2113.

67. Zhang L, Liu XJ: An improved probabilistic model for finding differential gene expression. Proc 2009 2nd Int Conf Biomed Eng Inform 2009, 1-4:1566-1571. 
68. Prifti E, Zucker JD, Clement K, Henegar C: FunNet: an integrative tool for exploring transcriptional interactions. Bioinformatics 2008, 24(22):2636-2638.

69. Clifford RL, Deacon K, Knox AJ: Novel regulation of vascular endothelial growth factor-A (VEGF-A) by transforming growth factor (beta)1: requirement for Smads, (beta)-CATENIN, AND GSK3(beta). J Biol Chem 2008, 283(51):35337-35353.

70. Easwaran V, Lee SH, Inge L, Guo L, Goldbeck C, Garrett E, Wiesmann M, Garcia PD, Fuller JH, Chan V, Randazzo F, Gundel R, Warren RS, Escobedo J, Aukerman SL, Taylor RN, Fantl WJ: beta-Catenin regulates vascular endothelial growth factor expression in colon cancer. Cancer Res 2003, 63(12):3145-3153.

71. Itoh F, Itoh S, Goumans M-J, Valdimarsdottir G, Iso T, Dotto GP, Hamamori Y, Kedes L, Kato M, Ten Dijke PP: Synergy and antagonism between Notch and BMP receptor signaling pathways in endothelial cells. EMBO J 2004, 23(3):541-551.

72. Kim TH, Xiong H, Zhang Z, Ren B: beta-Catenin activates the growth factor endothelin-1 in colon cancer cells. Oncogene 2005, 24(4):597-604.

73. Masckauchan TNH, Shawber CJ, Funahashi Y, Li C-M, Kitajewski J: Wnt/beta-catenin signaling induces proliferation, survival and interleukin-8 in human endothelial cells. Angiogenesis 2005, 8(1):43-51.

74. Patel NS, Li J-L, Generali D, Poulsom R, Cranston DW, Harris AL: Up-regulation of delta-like 4 ligand in human tumor vasculature and the role of basal expression in endothelial cell function. Cancer Res 2005, 65(19):8690-8697.

75. Shawber CJ, Das I, Francisco E, Kitajewski J: Notch signaling in primary endothelial cells. Ann N Y Acad Sci 2003, 995:162-170.

76. Vapnik V, Kotz S: Estimation of Dependences Based on Empirical Data: Empirical Inference Science. Secaucus, NJ, USA: Springer-Verlag New York, Inc; 2006.

doi:10.1186/1752-0509-8-80

Cite this article as: Aung et al: A systems biology analysis of brain microvascular endothelial cell lipotoxicity. BMC Systems Biology 2014 8:80.

\section{Submit your next manuscript to BioMed Central and take full advantage of:}

- Convenient online submission

- Thorough peer review

- No space constraints or color figure charges

- Immediate publication on acceptance

- Inclusion in PubMed, CAS, Scopus and Google Scholar

- Research which is freely available for redistribution 